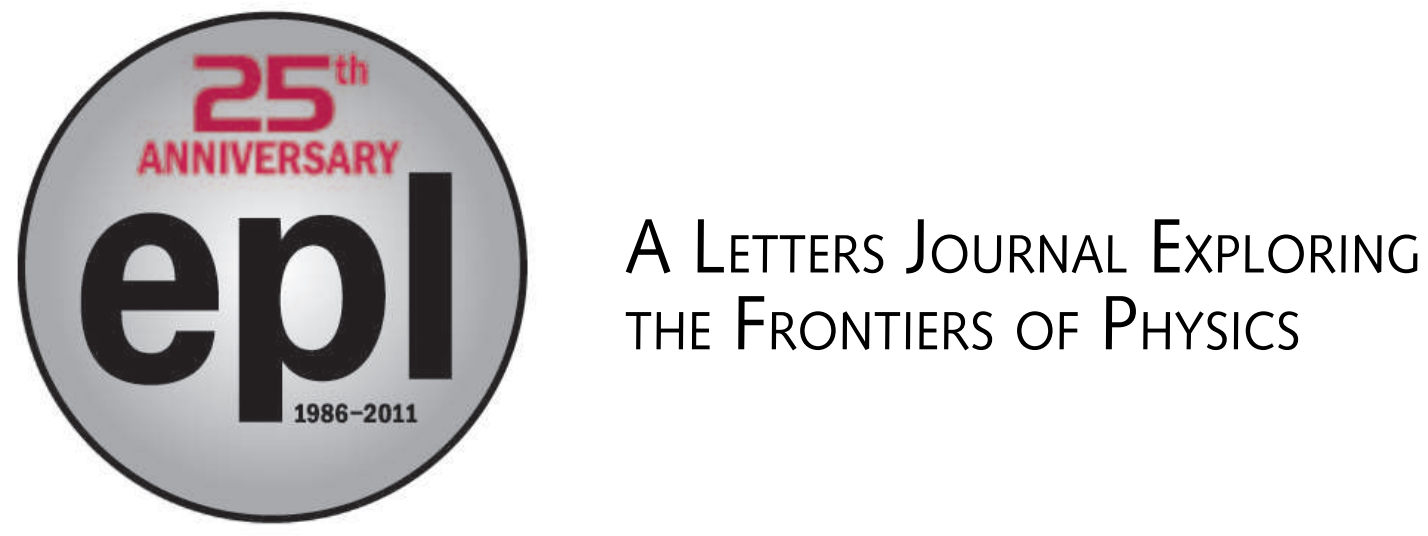

OFFPRINT

Flexibility windows and phase transitions of ordered and disordered ANA framework zeolites

\author{
S. A. Wells, A. Sartbaeva and G. D. Gatta \\ EPL, 94 (2011) 56001
}

Please visit the new website www . epl journal . org 


\section{A LETTERS JOURNAL EXPLORING THE FRONTIERS OF PHYSICS \\ The Editorial Board invites you to submit your letters to EPL www.epl journal.org}

\section{Six good reasons to publish with EPL}

We want to work with you to help gain recognition for your high-quality work through worldwide visibility and high citations. As an EPL author, you will benefit from:

1 Quality - The 40+ Co-Editors, who are experts in their fields, oversee the entire peer-review process, from selection of the referees to making all final acceptance decisions

2 Impact Factor - The 2009 Impact Factor increased by 31\% to 2.893; your work will be in the right place to be cited by your peers

3 Speed of processing - We aim to provide you with a quick and efficient service; the median time from acceptance to online publication is 30 days

4. High visibility - All articles are free to read for 30 days from online publication date

5 International reach - Over 2,000 institutions have access to EPL, enabling your work to be read by your peers in 100 countries

6 Open Access - Experimental and theoretical high-energy particle physics articles are currently open access at no charge to the author. All other articles are offered open access for a one-off author payment $(€ 1,000)$

Details on preparing, submitting and tracking the progress of your manuscript from submission to acceptance are available on the EPL submission website www.epletters.net

If you would like further information about our author service or EPL in general, please visit www.epljournal.org or e-mail us at info@epljournal.org 


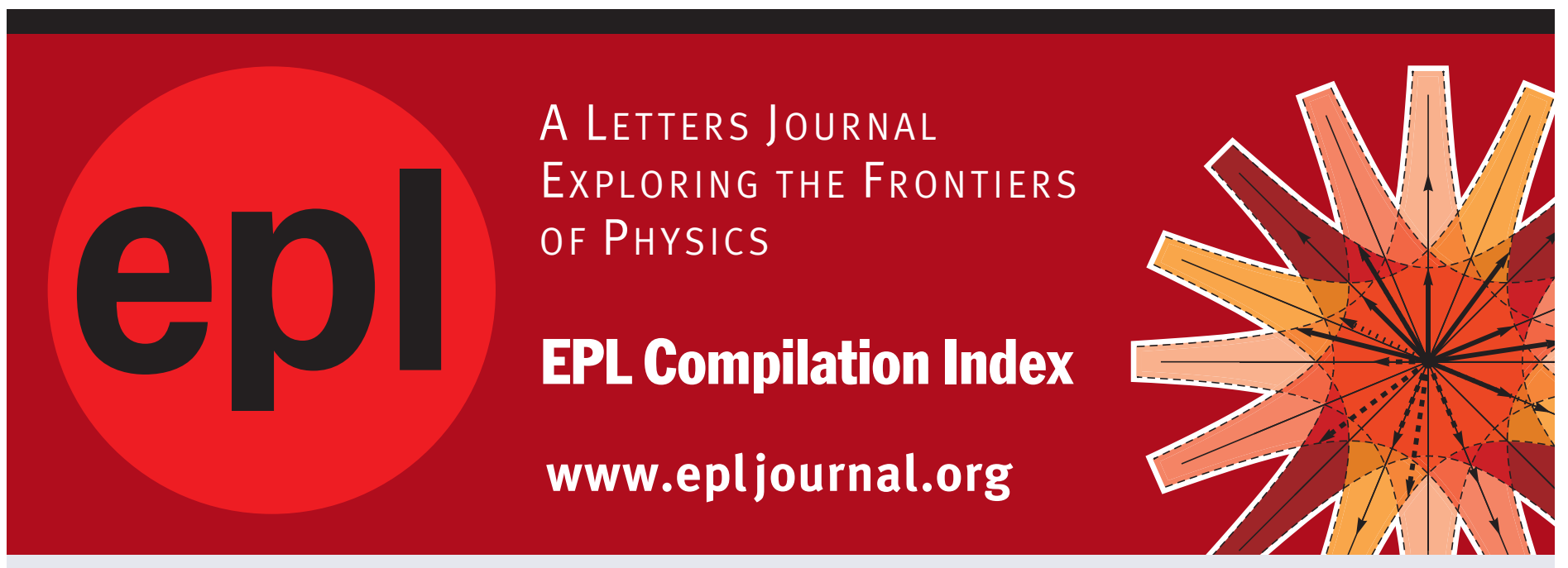

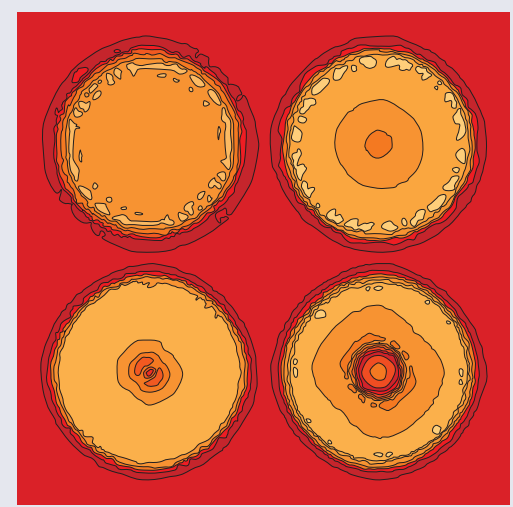

Biaxial strain on lens-shaped quantum rings of different inner radii, adapted from Zhang et al 2008 EPL 8367004.

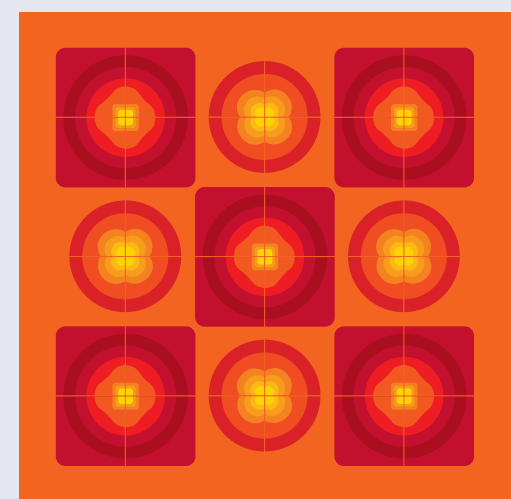

Artistic impression of electrostatic particle-particle interactions in dielectrophoresis, adapted from N Aubry and P Singh 2006 EPL 74623.

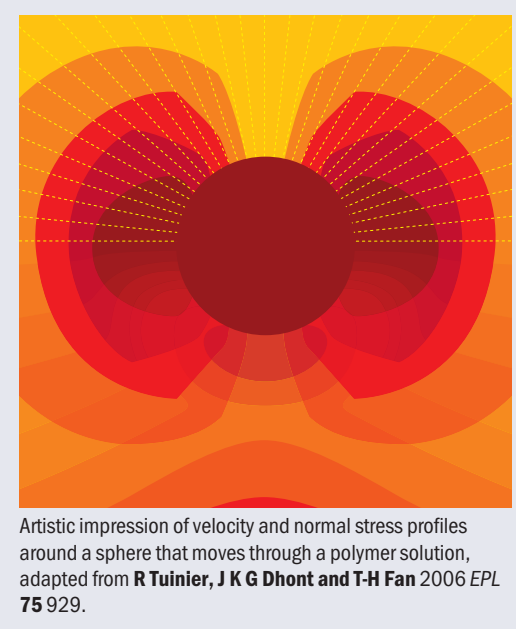

Visit the EPL website to read the latest articles published in cutting-edge fields of research from across the whole of physics.

Each compilation is led by its own Co-Editor, who is a leading scientist in that field, and who is responsible for overseeing the review process, selecting referees and making publication decisions for every manuscript.

- Graphene

- Liquid Crystals

- High Transition Temperature Superconductors

- Quantum Information Processing \& Communication

- Biological \& Soft Matter Physics

- Atomic, Molecular \& Optical Physics

- Bose-Einstein Condensates \& Ultracold Gases

- Metamaterials, Nanostructures \& Magnetic Materials

- Mathematical Methods

- Physics of Gases, Plasmas \& Electric Fields

- High Energy Nuclear Physics

If you are working on research in any of these areas, the Co-Editors would be delighted to receive your submission. Articles should be submitted via the automated manuscript system at www.epletters.net

If you would like further information about our author senvice or EPL in general, please visit www.epljournal.org or e-mail us at info@epljournal.org

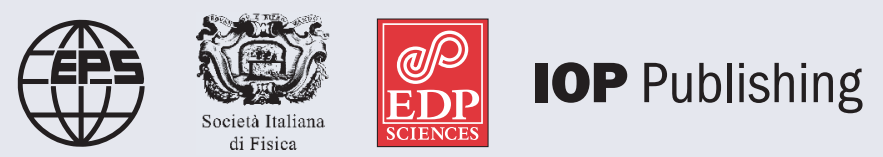

Image: Ornamental multiplication of space-time figures of temperature transformation rules (adapted from T. S. Bíró and P. Ván 2010 EPL 89 30001; artistic impression by Frédérique Swist). 


\title{
Flexibility windows and phase transitions of ordered and disordered ANA framework zeolites
}

\author{
S. A. Wells ${ }^{1(a)}$, A. Sartbaeva ${ }^{2}$ and G. D. Gatta ${ }^{3,4}$ \\ ${ }^{1}$ Department of Physics and Centre for Scientific Computing, University of Warwick - Gibbet Hill Road, \\ Coventry CV4 $7 A L, U K, E U$ \\ ${ }^{2}$ Inorganic Chemistry Laboratory, University of Oxford - South Parks Road, Oxford OX1 3QR, UK, EU \\ ${ }^{3}$ Dipartimento Scienze della Terra, Università degli Studi di Milano - Via Botticelli 23, I-20133 Milano, Italy, EU \\ ${ }^{4}$ CNR, Istituto per la Dinamica dei Processi Ambientali - Via Mario Bianco 9, I-20131 Milano, Italy, EU
}

received 11 April 2011; accepted 26 April 2011

published online 16 May 2011

PACS 61.50.Ks - Crystallographic aspects of phase transformations; pressure effects

PACS 64.60.Ej - Studies/theory of phase transitions of specific substances

PACS 81.30.Hd - Constant-composition solid-solid phase transformations: polymorphic, massive, and order-disorder

\begin{abstract}
The analcime-like feldspathoids are a group of microporous minerals with the ANA framework topology. Analcime proper has predominantly $\mathrm{Na}$ as its channel cation content, while leucite contains predominantly $\mathrm{K}$, pollucite contains $\mathrm{Cs}$ and wairakite contains Ca. Under compression, all these minerals display structural displacive phase transitions to low-symmetry forms at relatively low pressures $(0.5-3.2 \mathrm{GPa})$. We show, using geometric simulation, that these phase transitions are controlled by the "flexibility window" of the ANA framework, defined as the range of framework densities over which the tetrahedral units of the framework can in principle be made geometrically ideal. We discuss experimental compression data for these minerals and its relationship to the theoretical flexibility of the ANA framework, the influence of cation content, and framework ordering.
\end{abstract}

Copyright (C) EPLA, 2011

Introduction. - Many minerals have structures that can be described as a "framework" of linked polyhedra, with non-framework ions and molecules occupying spaces surrounded by the framework. Examples include the $\mathrm{AMO}_{3}$ perovskites, viewed as a framework of cornersharing $\mathrm{MO}_{6}$ octahedra with interstitial $\mathrm{A}$ ions, and the dense framework silicates such as quartz, with their framework of corner-sharing $\mathrm{SiO}_{4}$ tetrahedra. The zeolites [1] - a broad group of framework minerals whose cornersharing tetrahedral aluminosilicate frameworks contain cages, pores and channels large enough to contain not only ions but also $\mathrm{H}_{2} \mathrm{O}$ and other small molecules - are of particular interest in chemical industries [2,3] as molecular sieves, shape-selective catalysts and ion-exchange materials.

The polyhedra making up a crystalline framework are not usually geometrically ideal. Small distortions from perfect regularity are visible in crystal structures, due to electrostatic and steric interactions between framework

(a) E-mail: s.a.wells@warwick.ac.uk and extra-framework atoms/ions. The question naturally arises whether, absent such interactions, it is in principle possible to make the framework polyhedra perfectly regular, for a given set of unit-cell parameters and a given framework topology. This question of perfectibility can be answered using geometric simulation - a simulation method adapted for framework structures, in which the ideal bonding geometry of a polyhedral unit is represented by a template to which framework atoms are tethered by harmonic constraints [4]. The method of geometric simulation has been successfully applied in a number of studies on zeolites and other framework mineral structures [4-10].

It has recently been observed that known zeolite frameworks are typically perfectible over a wide range of densities [11]. This range is termed the "flexibility window". Under ambient conditions zeolite structures tend towards the low-density edge of their flexibility window. Although the flexibility window is an essentially geometric phenomenon, it has a physical significance [12]. If a structure lies within its flexibility window, so that its polyhedra can in principle be made perfectly regular, then 
small distortions of the polyhedra are variations about a minimum; their energy cost should therefore be secondorder in the size of the distortion. If on the other hand the structure lies outside its flexibility window, its polyhedra are intrinsically strained before other interactions are taken into account. The energy cost of further distortions should therefore be larger and first-order in the size of the distortion. There is thus an energetic incentive for structures to remain within their flexibility window. Given the known tendency of zeolite structures to respond to pressure through displacive mechanisms based on cooperative rotations of the framework polyhedra [13,14], we expect to find connections between the pressure behaviour of zeolites, particularly pressure-induced phase transitions, and the limits of the flexibility window.

The "analcime group" of minerals with the ANA framework topology includes the aluminosilicates analcime (or analcite) [15], leucite [16], wairakite [17-19] and pollucite [20]. These are compositional end members distinguished by the interstitial ions typically found in the structural channels. Analcime is the $\mathrm{Na}$ end member (ideally $\mathrm{Na}_{16} \mathrm{Al}_{16} \mathrm{Si}_{32} \mathrm{O}_{96} \cdot 16 \mathrm{H}_{2} \mathrm{O}$ ); it is commonly defined as a feldspathoid, though the Commission of the International Mineralogical Association includes analcime in the zeolite group [21]. Leucite contains $\mathrm{K}\left(\mathrm{K}_{16} \mathrm{Al}_{16} \mathrm{Si}_{32} \mathrm{O}_{96}\right)$, wairakite contains $\mathrm{Ca}$ $\left(\mathrm{Ca}_{8} \mathrm{Al}_{16} \mathrm{Si}_{32} \mathrm{O}_{96} \cdot 16 \mathrm{H}_{2} \mathrm{O}\right)$ and pollucite contains $\mathrm{Cs}$ $\left(\mathrm{Cs}_{12} \mathrm{Na}_{4} \mathrm{Al}_{16} \mathrm{Si}_{32} \mathrm{O}_{96} \cdot 12 \mathrm{H}_{2} \mathrm{O}\right)$. Leucite is the only nominally anhydrous member of the "analcime group" [22]. Hsianghualite $\left(\mathrm{Li}_{16} \mathrm{Ca}_{24} \mathrm{Be}_{24} \mathrm{Si}_{24} \mathrm{O}_{96} \mathrm{~F}_{16}\right)$ also has ANA framework topology, but is not a zeolitic aluminosilicate framework and we do not consider it further. The aluminosilicate end members have broadly similar behaviour under pressure, transforming displacively at relatively low pressures $(<1-3 \mathrm{GPa})$ from a high-symmetry ambient form to a very low-symmetry compressed form.

We have previously found [12] that the phase transition in cubic analcime occurs when the structure is compressed sufficiently that the cubic framework can no longer remain within its flexibility window. In a further study [23] we demonstrated that the same is true of tetragonal leucite. We also considered the behaviour of wairakite; however, geometric simulations of wairakite with a simplified uniform tetrahedral bond length (representing full $\mathrm{Al} / \mathrm{Si}$ disorder in the framework) did not match experimental data, as the simulations found that the framework was not perfectible within part of its cubic range. We tentatively attributed the discrepancy to $\mathrm{Si} / \mathrm{Al}$ order in the wairakite framework, as experimentally observed [17-19].

We now make use of geometrical simulation combined with experimental data on the compression behaviour of analcime, leucite, wairakite and pollucite, and of an $\mathrm{Al} / \mathrm{Si}$ ordered structure for wairakite, to connect the flexibility windows and pressure-induced phase transitions of all the end members of the analcime group.
Experimental data. - The high- $P$ behaviour under hydrostatic conditions of analcime, leucite and pollucite has been investigated by in situ X-ray singlecrystal diffraction with a diamond anvil cell up to $\sim 7-8 \mathrm{GPa}[15,16,20]$ and that of wairakite by in situ synchrotron powder diffraction up to $\sim 7.8 \mathrm{GPa}$ [19]. The structure refinement of analcime, leucite and pollucite at room conditions proved a disordered $\mathrm{Si} / \mathrm{Al}$-distribution in the tetrahedral framework. In contrast, the structure refinements of wairakite suggested a highly ordered Si/Aldistribution; for our simulation, we used the structure model of wairakite from [18]. All the four members of the ANA group experience a phase transition from highsymmetry to low-symmetry polymorph under pressure: 1) analcime, between $0.91(5)$ and 1.08(5) GPa from $I a \overline{3} d$ to $P \overline{1}$ symmetry; 2$)$ pollucite, between $0.54(4)$ and $0.79(3)$ GPa from $I a \overline{3} d$ to $P \overline{1}$ symmetry; 3 ) leucite, between 2.19(4) and 2.77(1) GPa from $I 4_{1} / a$ to $P \overline{1}$ symmetry; 4) wairakite, between 2.5(1) and 3.2(1) GPa from $I 2 / a$ to $P \overline{1}$ symmetry. For analcime and leucite, the $P$-induced phase transition is unambiguously a first-order transition; in contrast, for pollucite and wairakite the order of the transition cannot be unambiguously defined. The structural refinement of the low- $P$ and high- $P$ polymorphs of analcime showed that the $P$-induced phase transition at $\sim 1 \mathrm{GPa}$ is displacive in character [15]. Structure refinements of the high- $P$ polymorphs of pollucite, leucite and wairakite are not available. On the basis of the structural homology among the ANA members, we can expect the same displacive character of the $P$-induced transition in pollucite, leucite, and wairakite.

Simulation methods. - The method of geometric simulation has been described in detail in the literature $[4$, $7,8,11]$. Briefly, the input to the simulation is a cell or supercell of a framework structure, with all framework atoms represented and without symmetry constraints on atomic positions (that is, with $P 1$ symmetry), and a set of polyhedral specifications describing the shape and size of bonded units (e.g. a $\mathrm{SiO}_{4}$ tetrahedron with bond length $1.61 \AA$ ). Hard-sphere steric radii are also given; as is conventional for zeolite studies [1] we assign a radius of $1.35 \AA$ to framework oxygen atoms, whose collision typically limits the flexibility window at high densities. Each bonded unit identified in the framework is assigned an appropriately shaped polyhedral template; harmonic constraints penalise displacements of the atoms from the vertices of the templates. In a geometric relaxation, the positions of all atoms and the positions and orientations of all templates are relaxed together so as to determine whether it is possible to bring all atoms within a small tolerance $(0.001 \AA)$ of ideal polyhedral geometry.

Geometric simulations are carried out using the program GASP, originally developed by SAW [4]. In this study we make use of a recent improvement to the code, the implementation of the limited-memory BFGS algorithm [24] by Dr. Kapko as reported in [25], which 


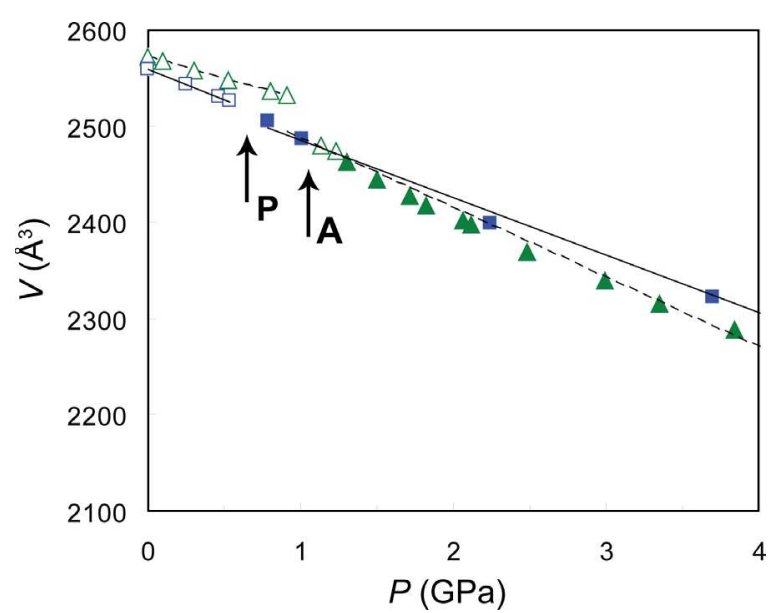

Fig. 1: (Colour on-line) $P-V$ data for analcime (triangles) and pollucite (squares) annotated with results of geometric simulation. Points are labelled with open symbols if the framework is found to be perfectible and with closed symbols if the framework is intrinsically distorted. For both, the ambient/low- $P$ structure is perfectible, while the high- $P$ structure is generally not. Locations of the phase transitions of analcime (A) and pollucite $(\mathrm{P})$ are indicated by arrows.

greatly accelerates geometric relaxation compared to the previous steepest-descent minimiser.

Analcime, leucite and pollucite frameworks are modelled using an averaged T-O bond length of $1.65 \AA$, representing an appropriate weighted average of the $\mathrm{Si}-\mathrm{O}$ and $\mathrm{Al}-\mathrm{O}$ bond lengths $[12,23]$ for a fully disordered framework. We have previously found that this disordered model does not match the experimental data for wairakite. Highly ordered $\mathrm{Si} / \mathrm{Al}$-distribution in wairakite structure have been reported [18,26]; accordingly, we model wairakite framework using distinct $\mathrm{Si}$ and $\mathrm{Al}$ sites, for which bond lengths of $1.61 \AA$ for $\mathrm{Si}-\mathrm{O}$ and $1.75 \AA$ for $\mathrm{Al}-\mathrm{O}$, respectively, are used.

For each $P-V$ point where unit-cell parameters are available for a structure, we impose the given parameters on a model of the framework and use geometric relaxation to determine the perfectibility of the structure. We also determine the theoretical limits of the flexibility window for the cubic framework of pollucite by looping over a range of densities.

Results. - In fig. 1 we summarise the results of geometric simulation at experimental $P-V$ data points for analcime and pollucite, while in fig. 2 we consider noncubic forms: leucite and wairakite. Analcime and pollucite are cubic $(I a \overline{3} d)$ under ambient conditions, leucite is tetragonal $\left(I 4_{1} / a\right)$ and wairakite is monoclinic $(I 2 / a)$. All structures transform under pressure to very low-symmetry $(P \overline{1})$ triclinic forms.

Points are labelled with open symbols if the framework is found to be perfectible (that is, it lies within the flexibility window) and with closed symbols if the framework is intrinsically distorted. It is clear that the behaviour of all four aluminosilicate end members follows the same

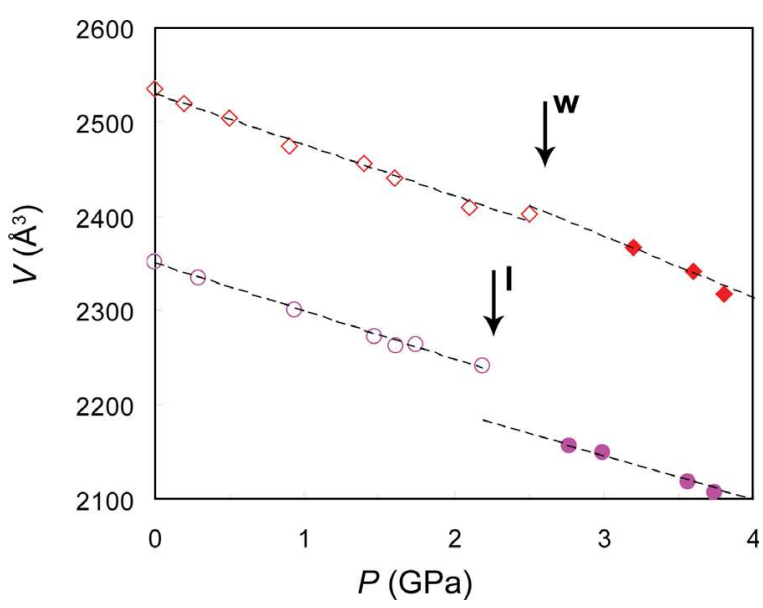

Fig. 2: (Colour on-line) $P-V$ data for wairakite (diamonds) and leucite (circles) annotated with results of geometric simulation. Points are labelled with open symbols if the framework is found to be perfectible and with closed symbols if the framework is intrinsically distorted. For both, the ambient/low- $P$ structure is perfectible, while the high- $P$ structure is not. Locations of the phase transitions of wairakite $(\mathrm{W})$ and leucite $(\mathrm{L})$ are indicated by arrows.

pattern; the ambient/low- $P$ structure is perfectible while the compressed structure is generally not. We note that in analcime some data points for the compressed structure are also perfectible.

Comparison with earlier results [23] indicates that $\mathrm{Si} / \mathrm{Al}$ ordering in the wairakite structure widens its flexibility window; in a disordered model of the wairakite cell, all points above $P=0.9 \mathrm{GPa}$ are not perfectible. This is consistent with the recent observation [25] that ordering can make structures relaxable for which a pure-silica model form is intrinsically strained.

It is conventional, when discussing zeolite structures, to use "framework density", defined as the number of tetrahedral units per $1000 \AA^{3}$. The analcime group are among the densest of zeolites; under ambient conditions, framework densities are $18.64 \mathrm{~T} / \AA^{3}$ for cubic analcime and $18.76 \mathrm{~T} / \AA^{3}$ for cubic pollucite, $18.93 \mathrm{~T} / \AA^{3}$ for monoclinic wairakite, and $20.38 \mathrm{~T} / \AA^{3}$ for tetragonal leucite.

This survey of experimental data points implicitly provides information on the limits of the flexibility window of the low- $P$ structure. We expect the limit to lie between the last observed density of the low- $P$ structure, where it is still perfectible, and the first observed density of the high- $P$ structure. For the cubic structures (analcite and pollucite) we can easily compare these experimental limits on the flexibility window with the theoretical limit, obtained by uniformly scaling the cubic unit-cell to cover a range of densities around the ambient value.

To parallel the calculations previously carried out on analcime [12] we perform simulations of the cubic framework of pollucite, starting at the observed ambient framework density $\left(18.76 \mathrm{~T} / \AA^{3}\right)$ and progressively compressing or expanding the simulation cell. On compression we find 
the edge of the flexibility window at a framework density of around $19.17 \mathrm{~T} / \AA^{3}$. Pollucite is observed in its cubic form at a framework density of $19.01 \mathrm{~T} / \AA^{3}$ at a pressure of $0.54 \mathrm{GPa}$ and, after the phase transition, is observed in its triclinic form at a framework density of $19.16 \mathrm{~T} / \AA^{3}$ at a pressure of $0.79 \mathrm{GPa}$. The transition from cubic to triclinic in pollucite thus occurs just at the edge of the flexibility window for the cubic framework of pollucite; the match is surprisingly close given the extreme simplicity of our simulation model.

Simulation of expansion (which is, of course, not experimentally observed) finds an upper limit of the flexibility window at a framework density of $18.58 \mathrm{~T} / \AA^{3}$. Both analcime and pollucite thus lie towards the less dense edge of the flexibility window, consistent with the behaviour of other zeolite frameworks [11].

Discussion. - We have considered experimental data and simulation results for all four end members of the analcime group of aluminosilicate zeolites. We can now confirm our conjecture $[12,23]$ that the pressure-induced phase transitions of aluminosilicates in the analcime group are controlled by the flexibility window of the framework. Our geometric simulations concern only the framework and do not include the ions and water molecules lying in the channels. There is a very wide variation in the ionic content of the end members of the group, and leucite is anhydrous while the other members are hydrated. We nonetheless find common behaviour for all four endmember minerals, with the ambient/low- $P$ structure being perfectible while the high- $P$ form is intrinsically distorted.

This suggests that the phase transitions of these minerals are effectively controlled by the self-interactions of the framework; the effect of the ionic content on the transition is indirect rather than direct. That is, the ionic content presumably influences the ambient crystal structure (cubic, tetragonal or monoclinic), which in turn affects the flexibility window; we have seen that tetragonal leucite is relaxable at densities far beyond the flexibility window of the cubic analcime or pollucite framework. However, the ionic content does not maintain an analcime structure in its high-symmetry form if the framework is not perfectible. This is in contrast to a recent result on goosecreekite [25] which appears to be stabilised in a non-perfectible form by ion/framework interactions; goosecreekite contains divalent cations, as does wairakite.

The inclusion of ordering in wairakite makes certain structures perfectible which, in a fully disordered simulation using a single uniform tetrahedral size, would be intrinsically distorted. It may at first seem counterintuitive that the inclusion of ordering should make the geometric relaxation easier. In effect, however, we are introducing additional degrees of freedom to the system by allowing different polyhedral sizes, while not introducing additional distance constraints.

We may speculate that the unusually high density of the analcime group is connected to the dominance of the framework in the pressure-induced phase transition. The influence of the flexibility window of less dense zeolites on their pressure-induced phase transitions will be an interesting avenue of research.

$$
* * *
$$

We would like to acknowledge stimulating discussions with Dr. V. Kapko, Prof. M. F. Thorpe and Prof. M. M. J. Treacy (ASU). AS thanks the Glasstone Research Fellowship and the Royal Society for funding, and SAW thanks the Leverhulme trust. The authors will be grateful to an anonymous reviewer for constructive and helpful comments.

\section{REFERENCES}

[1] Baerlocher Ch., Meier W. M. and Olson D. H., Atlas of Zeolite Framework Types (Elsevier, Amsterdam) 2001.

[2] Breck D. W., Zeolite Molecular Sieves (Krieger, Malabar, Fla.) 1984.

[3] Davis M. E., Nature, 417 (2002) 813.

[4] Wells S. A., Dove M. T. and Tucker M. G., J. Appl. Crystallogr., 37 (2004) 536.

[5] Gatta G. D. and Wells S. A., Phys. Chem. Miner., 31 (2004) 465.

[6] Gatta G. D. and Wells S. A., Phys. Chem. Miner., 33 (2006) 243.

[7] Wells S. A., Dove M. T. and Tucker M. G., J. Phys.: Condens. Matter, 14 (2002) 4567.

[8] Sartbaeva A., Wells S. A. and Redfern S. A. T., J. Phys.: Condens. Matter, 16 (2004) 8173.

[9] Sartbaeva A., Wells S. A., Redfern S. A. T., Hinton R. W. and Reed S. J. B., J. Phys.: Condens. Matter, 17 (2005) 1099.

[10] Sartbaeva A., Wells S. A., Thorpe M. F., Bozin E. S. and Billinge S. J. L., Phys. Rev. Lett., 97 (2006) 065501.

[11] Sartbaeva A., Wells S. A., Treacy M. M. J. and Thorpe M. F., Nat. Mater., 5 (2006) 962.

[12] Sartbaeva A., Gatta G. D. and Wells S. A., EPL, 83 (2008) 26002.

[13] Gatta G. D., Eur. J. Mineral., 17 (2005) 411.

[14] Gatta G. D., Z. Kristallogr., 223 (2008) 160.

[15] Gatta G. D., Nestola F. and Boffa Ballaran T., Am. Mineral., 91 (2006) 568.

[16] Gatta G. D., Rotiroti N., Boffa Ballaran T. and Pavese A., Am. Mineral., 93 (2008) 1588.

[17] Takeuchi Y., Mazzi F., Haga N. and Galli E., Am. Mineral., 64 (1979) 993.

[18] Henderson C. M. B., Bell A. M. T., Kohn S. C. and Page C. S., Mineral. Mag., 62 (1998) 165.

[19] Ori S., Quartieri S., Vezzalini G. and Dmitriev V., Am. Mineral., 93 (2008) 53.

[20] Gatta G. D., Rotiroti N., Boffa Ballaran T., Sanchez-Valle C. and Pavese A., Am. Mineral., 94 (2009) 1137.

[21] Coombs D. S., Alberti A., Armbruster T., Artioli G., Colella C., Galli E., Grice J. D., Liebau 
F., Mandarino J. A., Minato H., Nickel E. H., Passaglia E., Peacor D. R., Quartieri S., Rinaldi R., Ross M., Sheppard R. A., Tillmanns E. and Vezzalini G., Can. Mineral., 35 (1997) 1571.

[22] Gatta G. D., Rotiroti N., Bellatreccia F. and Della Ventura G., Mineral. Mag., 71 (2007) 679.
[23] Gatta G. D., Sartbaeva A. and Wells S. A., Eur. J. Mineral., 21 (2009) 571.

[24] Nocedal J., Math. Comput., 35 (1980) 773.

[25] Kapko V., Dawson C., Treacy M. M. J. and Thorpe M. F., Phys. Chem. Chem. Phys., 12 (2010) 8531.

[26] Mazzi F. and Galli E., Am. Mineral., 63 (1978) 448. 